\title{
Small Scale Materials Behavior from X-ray Microdiffraction and Imaging: Part II
}

\author{
Rozaliya I. Barabash
}

This special set of papers is a continuation of the topic started in the JOM December 2010 issue. $^{1-4}$ It highlights several novel applications of xray microdiffraction and imaging to study structural properties of materials at small length scales. The development of ultra-brilliant synchrotron x-ray sources together with the development of new software provides new insights for the analysis of local material structures at the meso- and nanoscales.

The special JOM topic starts with a manuscript by Kerber et al. which presents the state-of-the-art x-ray line profile analysis. The authors demonstrate that $\mathrm{x}$-ray line-profile analysis can be very useful for quantifying structural parameters in nanomaterials. The authors use this method to study dislocation distributions in crystalline materials. They present models for line broadening effects caused by finite crystallite size, lattice strain, planar faults, internal stresses, and point defects. Several example applications for nanostructured materials are described. This manuscript shows that modern line-profile-analysis is a useful tool for studies of nanomaterials.

The next paper, by Lienert et al., describes high-energy diffraction microscopy (HEDM) at the Advanced Photon Source. These experiments can provide important information about deformation and structure evolution at the mesoscale. HEDM can be performed in the two possible geometries: near-field and far-field. Near-field geometry is used for mapping grain boundary topology, while far-field geometry gives infor- mation about strain/stress evolution in individual grains during in-situ loading. Lattice strain tensors can be measured with resolution of the order of $10^{-4}$. In near-field microstructure mapping, the beam is focused in one dimension and remains unfocused in the other dimensions. Measurements in the far-field geometry are illustrated by inter-granular strain mapping and high-resolution reciprocal space mapping. The far-field geometry has a potential for understanding inter- and intra-granular micromechanical deformation processes such as deformation partitioning among different grains within a polycrystalline aggregate and dislocation structure evolution. This method complements studies of strain partitioning described in Reference 5. The authors show that during deformation the dislocations in copper self-organize, evolving into heterogeneous so-called "cell-wall" structures, ${ }^{6,7}$ and form dislocation-depleted regions with relatively small dislocation densities separated by dislocationrich walls.

The final paper is by Borbély et al., who apply in-situ microtomography to study the power law creep and creep damage in structural materials. They show that microtomography is a useful tool to characterize inhomogeneous specimen deformation. In-situ fast tomography was performed at the European Synchrotron Radiation Facility. The authors developed special software for tomographic reconstruction to account for characteristic noise reduction during in-situ measurements. Monitoring the macroscopic specimen shape allowed authors to evaluate the activation energy under temperature gradients. Comparing their experimental results with the theoretical growth rate of voids, the different growth behavior of voids in copper and brass was found. Based on the observations, the authors suggested the existence of two stable void growth regimes. The combination of the unique capabilities of modern high-brilliance x-ray sources with scientific instrumentation, hardware and software development described in the above papers demonstrates a new epoch in diffraction studies of materials at different length scales.

\section{ACKNOWLEDGEMENT}

R.B. is supported by the Materials Sciences and Engineering Division, Office of Basic Energy Sciences, U.S. Department of Energy.

\section{References}

1. W. Ludwig, A. King, M. Herbig, P. Reischig, J. Marrow, L. Babout, E.M. Lauridsen, H. Proudhon, and J.Y. Buffiere, JOM, 62 (12) (2010), pp. 22-28.

2. O.M. Barabash, M. Santella, R.I. Barabash, G.E. Ice, and J. Tischler, in Ref. 1, pp. 29-34.

3. H. Van Swygenhoven and S. Van Petegem, in Ref. 1, pp. 36-43.

4. Ralph D. Nyilas, Stephan Frank, and Ralph Spolenak, in Ref. 1, pp. 44-51.

5. R.I. Barabash, H. Bei, G.E. Ice, Y.F. Gao, and O.M. Barabash, JOM, 63 (3) (2011), pp. 30-34.

6. H. Mughrabi, and T. Ungar, Nature Materials, 5 (2006), pp. 601-602.

7. L.E. Levine, B.C. Larson, W. Yang, M.E. Kassner, J.Z. Tischler, M.A. Delos-Reyes, R.J. Fields, and W. Liu, Nature Materials, 5 (2006), pp. 619-622.

Rozaliya I. Barabash is with the MST Division, Oak Ridge National Laboratory, Oak Ridge TN 378316118 , and guest editor for the Mechanical Behavior of Materials Committee of the TMS Structural Materials Division.

\section{Rozaliya I. Barabash is a TMS Member!}

To read more about her, turn to page 8. To join TMS, visit www.tms.org/Society/Membership.aspx. 